\title{
Clinical management of a young man with ITP and symptomatic splenomegaly
}

\author{
Jordan Brown ${ }^{1}$, Santroy Samuels ${ }^{1}$, and Paramjeet Singh ${ }^{1}$ \\ ${ }^{1}$ Garnet Health Medical Center
}

February 12, 2022

\begin{abstract}
Idiopathic Thrombocytopenia and Splenomegaly are two well known pathologies that often can be managed medically. However there are instances in which surgical management is indicated. We report the proper management of a young man with splenomegaly and hypersplenism refractory to medical treatment with a history of Idiopathic Thrombocytopenia.
\end{abstract}

\section{Hosted file}

Clinical_Case_Reports_Submit .docx available at https://authorea.com/users/460139/articles/ 556189-clinical-management-of-a-young-man-with-itp-and-symptomatic-splenomegaly 


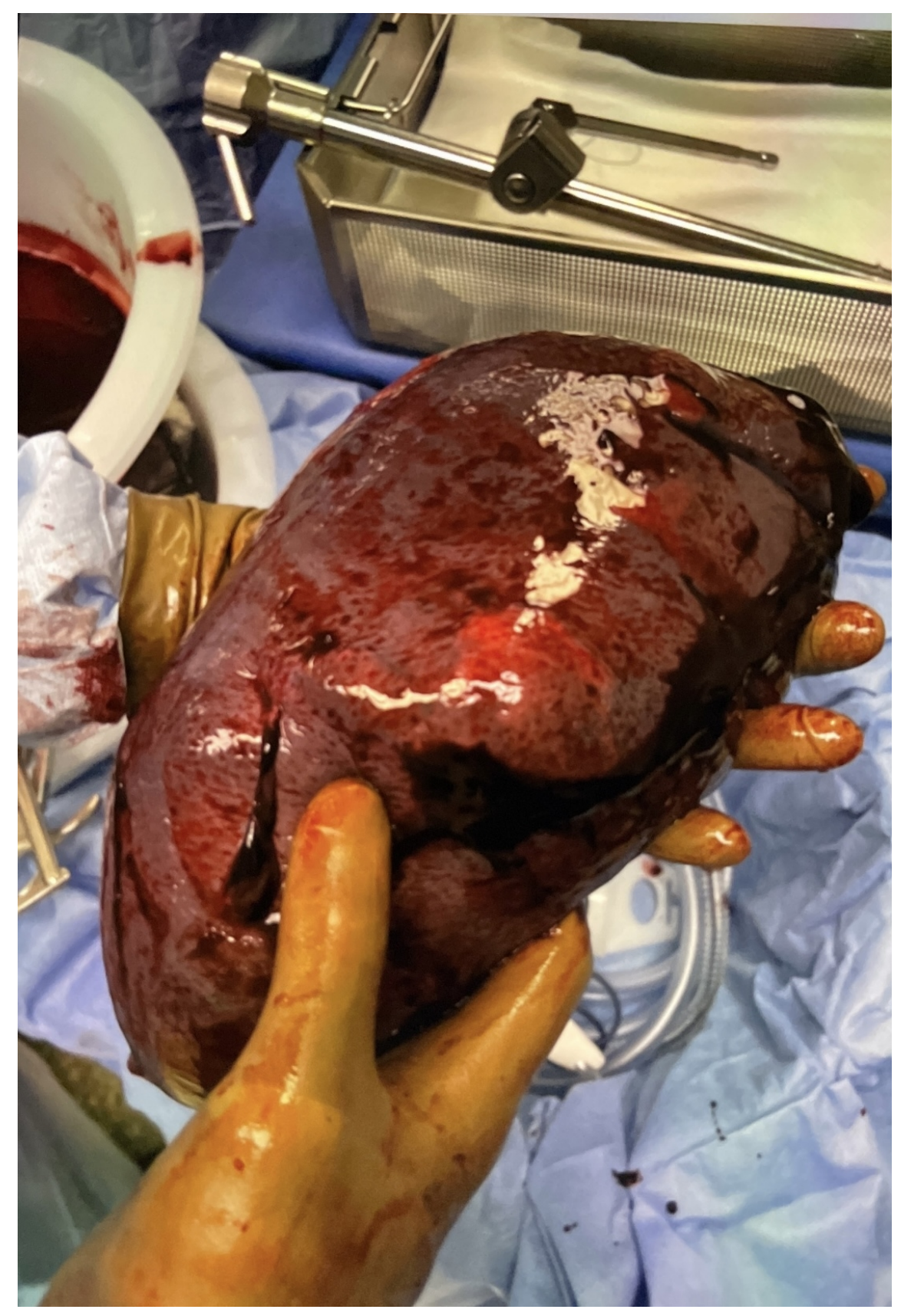




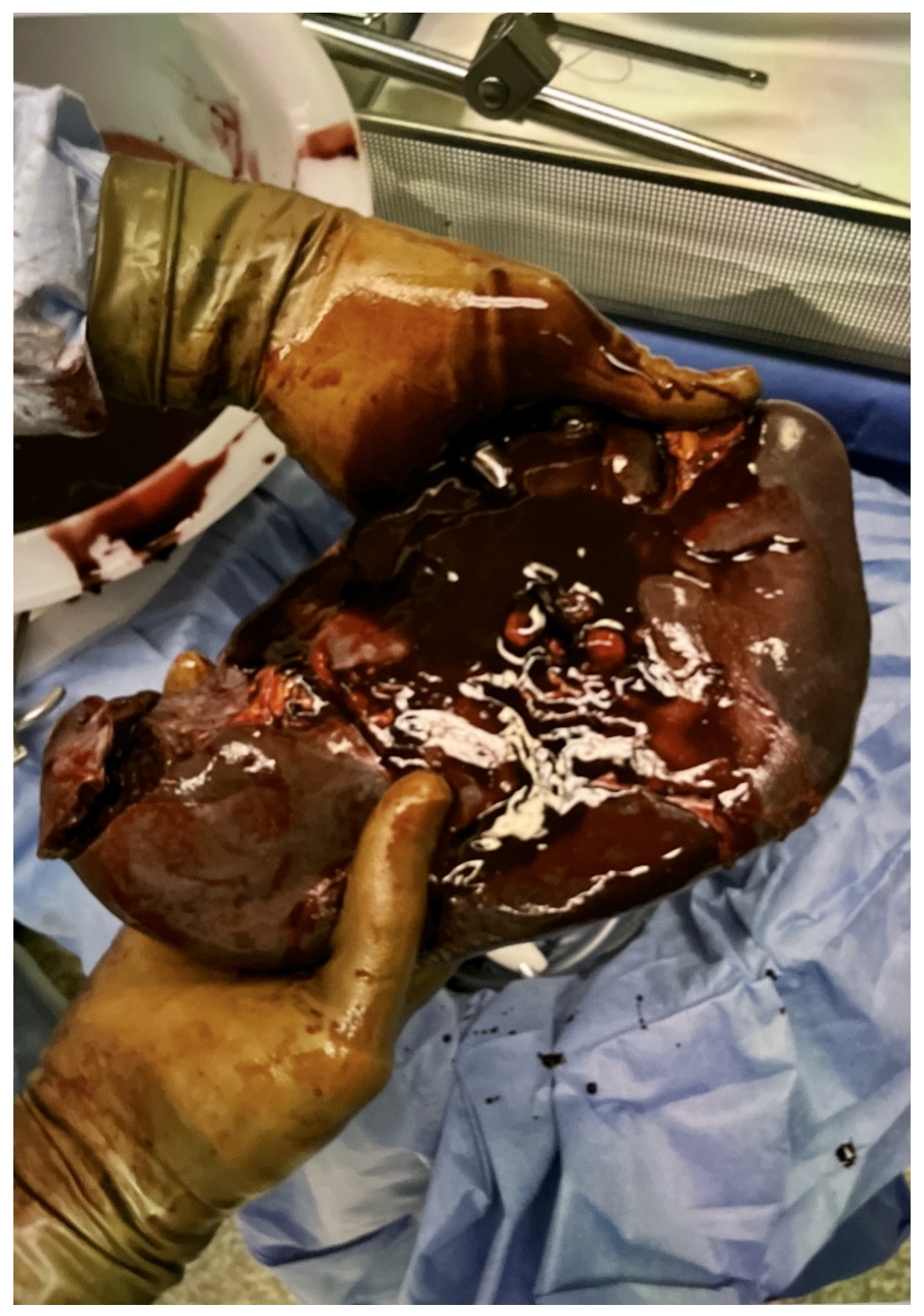

